\title{
Study on the Attenuation Mechanism of Unsaturated Residual Soil Under Rainfall Condition -A Case Study of the Tiller and Sediment Soil in Qishan Landslide, China
}

\author{
Liu Junzhe, Zuo Changqun, Song Yingjie, Ren Rui, Li Zi \\ Engineering Faculty, China University of Geosciences (Wuhan), Wuhan, China \\ Email address: \\ davidliu1993@outlook.com (Liu Junzhe),helenzz@126.com (Zuo Changqun)
}

To cite this article:

Liu Junzhe, Zuo Changqun, Song Yingjie, Ren Rui, Li Zi. Study on the Attenuation Mechanism of Unsaturated Residual Soil Under Rainfall Condition -A Case Study of the Tiller and Sediment Soil in Qishan Landslide, China. American Journal of Civil Engineering.

Vol. 5, No. 4, 2017, pp. 242-253. doi: 10.11648/j.ajce.20170504.18

Received: May 6, 2017; Accepted: July 31, 2017; Published: August 14, 2017

\begin{abstract}
In the most area of the Southern part in China, the high-intensity and large-scale rainfalls would easily cause some natural disasters like landslide and mud slide in the area of which the geological conditions are not stable and could lead to mass casualty and a great loss in economy. The paper targets the tuff residual soil in Qishan, Yongtai city, Fujian Province of China as the investigated subject, getting the mineral composition of the soil mass through X-ray experiment, analyzing the micro structure and mineral compositions in soil mass in qualitative, getting the parameters of shear strength of the soil mass by taking quadruple shear test to the soil samples which were in different level of water content and wet-dry cycle times, making analysis to the micro structure of test samples by using electrical scanning, and using the Matlab software to make calculation about the micro-structural parameters to analyze it in quantitative and forming the fitting relations among water content, wet-dry cycle times, vertical load and micro-structural parameters of soil mass so that the intensity attenuation mechanism of the unsaturated residual soil under the condition of rainfall would be revealed.
\end{abstract}

Keywords: Residual Soil Slope, Microstructure, Scanning Electron Microscope, Shear Strength, Intensity Attenuation Mechanism

\section{Introduction}

\subsection{Present Research Status of the Mechanism of Landslide Cause}

The mechanism of landslide is a dynamic change process from stable to failure status in structure under influences of all kinds internal and external factors in some certain geological condition slopes. Figuring out sliding mechanism of landslide could not only provide some theoretical foundation for landslide early-warning and disaster prevention and control, but also is a main research topic for a long period of time. Some Chinese and international researchers have made a great achievements by considering geological conditions, physical mechanism and the influences of all kinds internal and external factors and then making further analysis from the perspective of Engineering geology and geomechanics [1]. According to analyzing the 11 major landslide cases in China from $20^{\text {th }}$ century, Huang Runqiu [2] concluded the mechanisms and triggers of landslides are not completely same for slopes under different geological conditions and slope structures [3]. According to the different triggers and causes, Liu Chuanzheng etc. have defined the slopes as 9 different types including Collapsing landslide type, Rainfall creep landslide type and Freeze-slide type etc. by making further research on representative landslide cases [4].

Liu Chuanzheng, based on the investigation of the representative landslide events, has divided them into 9 types including collapse type, rainfall creep type and thaw collapse type [4]. According to the analysis of the form of landslide deformation, Varnes. D J [5] has divided the slope deformation and failure into six forms; E. Hoek and J. Bray have studied the mechanical mechanism of slope failure, the types of failure [6], the determination of shear strength and the method of wedge analysis; Sassa has analyzed the mechanism of landslide liquefaction under rapid undrained condition, and 
analyzed the effect of pore water pressure on debris flow in high speed remote landslide [7]; Erisman has studied the collapse, the destabilization, the disintegration and the movement mechanism in detail in the monograph "Rock Slide and Collapse Dynamics" [8]. Xing Aiguo [9] has obtained the hydrodynamic mechanism of large scale high speed landslide by a large number of laboratory tests. Wu Jian has modeled the relative motion characteristics of slip soil during the shearing process based on he transmission characteristics of the slip soil particles and then studied the stress distribution and material characteristics of soil band [10]. Xu Jiancong [11], through engineering examples, using unbalanced thrust method and numerical simulation method, has showed the key factors that caused the middle and deep gravel soil landslide failure is the heavy rainfall in long time and then has provided the evaluation of the landslide stability and prediction method [12]. In terms of time effect, Saito Michiko has divided clayey soil slope failure into primary creep, steady creep and accelerated creep and has studied the law of creep failure in detail which has been then applied to the actual landslide prediction [13]. Zhang Luxin, using the East River landslide as the research object, has analyzed its slide mechanism by the results of indoor investigation and has obtained the instability mechanism and the cause of creep landslide. [14]

In conclusion, the research on the mechanism of slope damage has become increasingly perfect. However, with the global climate change, frequent earthquake and human engineering activities, the influencing factors of landslide are gradually more complicated and the landslide mechanism will become diversified and unique.

\subsection{Current Research Status on Soil Microstructures}

Soil microstructure, which means soil particles are changed to special status in shape, size and arrangement aspects under their interaction effects [15], has mainly been researched in three aspects. The first is to make some treatments and analysis on soil microstructural images to get the key quantization parameters in structure. Second, according to fractal dimension theory, make quantitative researches and analysis on soil microstructure. The third aspect is to use computer technology to obtain its vital quantization parameters [16]. Wu Yixiang [17] has created and developed a quantitative analytical system for soil microstructural images which could help to figure out the relationship between the changing of soil microstructure and special mechanical properties of clay. Shi Bin [18] made some evaluation and judgments on the soil structural properties by make some quantitative researches on the structural directionality and ordering of some clayey soil.

The fractal theory has been applied to a lot of researches of soil microstructure since 1990s. Xiao Shufang [19] proposed the theory that granularity fractal could be used to characterize inhomogeneity of clayey soil. Xie Heping [20] proposed a measuring method of pore fractal. By using the fractal calculation method of Hous-doff, Hu Ruilin [21] analyzed the influences of soil particle size and arrangements, surface featured fractal dimension, pores and contact zone distribution fractal dimension for soil engineering properties. Wang Qing [22] measured pores in soil and made a clear partition for pores in clayey soil based on mercury intrusion method.

Wang Baojun [23] took advantage of Photoshop software to transform grey-scale images to binary images and make them vectorization with ARCGIS. Then, the equivalent area and perimeters were obtained by using GIS. And the Excel was used to calculate the fractal dimension of particle morphology. When making analysis on soil microstructure, it is greatly common to use VIDEOLAB system to obtain parameters, DIPIX to pretreat images [24] and quantitative analysis system to analyze data. Also, it is possible to use computer technology like GIS to realize indirect obtaining of the data [25].

\section{Basic Information of the Researched Slope}

The landslide site locates in the mountain which is behind Dongmen Qishan village in Yongtai City, Fujian Province in China. It is about $3 \mathrm{~km}$ away from center of the city. The site is located in the eroded high hill landscape. The original mountain whose original slope is $20-35^{\circ}$ is convex slope and rounded. The vegetation mostly fruit trees, pine trees and shrubs on the slope develops well. The flat site excavated at the toe of slope is the residential building. After May 2010, there were several crescent-shaped cracks in the slope elevation of 137 170 m. The lengths of cracks were between $40 \sim 60 \mathrm{~m}$ and their width were $20 \sim 30 \mathrm{~cm}$. All of them are tensile cracks and their depths were 1 3 $\mathrm{m}$. Soil collapse occurred on the slope between height of 127 137 m. After the signs of the landslide, the emergency unloading was carried out by the ways of 8 stages excavating in the middle of the slope based on the slope ratio of $1: 1.25$ to $1: 1$, providing the inner side of each platform with a simple sink drain towards lower parts of southeast. The vegetation was destroyed and the rock and soil was exposed directly to the atmosphere, like Figure 1 showed below:
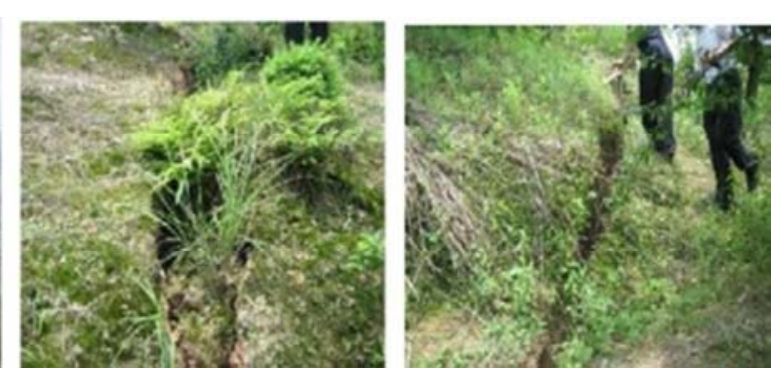

Figure 1. Pictures of conditions in the site. 
The site is located in an inclined structure on the eastern side of which there is a north to south right strike translational faults. In field investigation, a north-east fault is developed in the middle and lower part of the south slope of the site, and its origin $\mathrm{NE} 70^{\circ} / \mathrm{NW} \angle 65^{\circ}$. The site is situated at the junction of the North East trending structure and the North South structure affected by the tectonic and intrusive processes. The site is extremely fragmented and the groundwater is easily gathered in the syncline core. The slope rock mass is a representative tuff in Fujian Province. According to the data of borehole reconnaissance, the slip zone is mainly located in tuff area, so the weathered residual soil of tuff is chosen as the object of study. The landslide site quality diagram is shown in Graph 2:

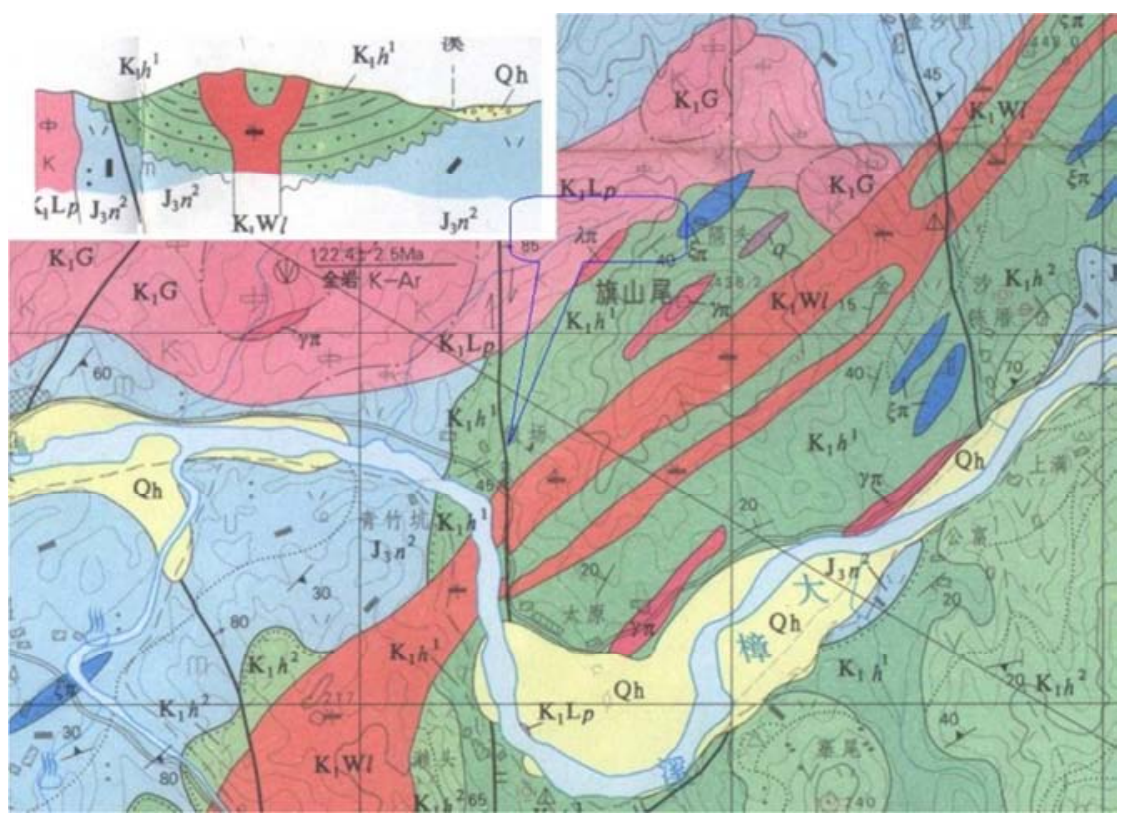

Figure 2. The geology map of landslide site area.

Through the geological survey, reconnaissance, deep displacement monitoring and other means for comprehensive judgments, Yongtai East Gate Qingshan landslide is irregular curve, of which the overall length is about $170 \mathrm{~m}$, the main slip direction is $\mathrm{W} 270^{\circ}$, the spindle length is about $165 \mathrm{~m}$, the front width is about $175 \mathrm{~m}$ and landslide area is about $24000 \mathrm{~m}^{2}$. The overall plane of landslide is trumpet shaped, with narrow back edge and gradually widened front edge.

Since May 2010, under the influence of human activities and natural factors, the slope on the north side of the cove and the trailing edge appear respectively a series of settlement cracks tensile cracks. At the end of August 2011, under the influence of the strong typhoon "Nanmadol", the cracks expanded. At the same time, due to cutting slope and taking few other slope protection measures, rock and soil have been directly exposed. Caused by multiple rainfall surface runoff erosion, the slope forms several shades of longitudinal slope gully, the maximum depth of which was $0.3 \mathrm{~m}$. The back tension fracture photos are shown in Figure 3:
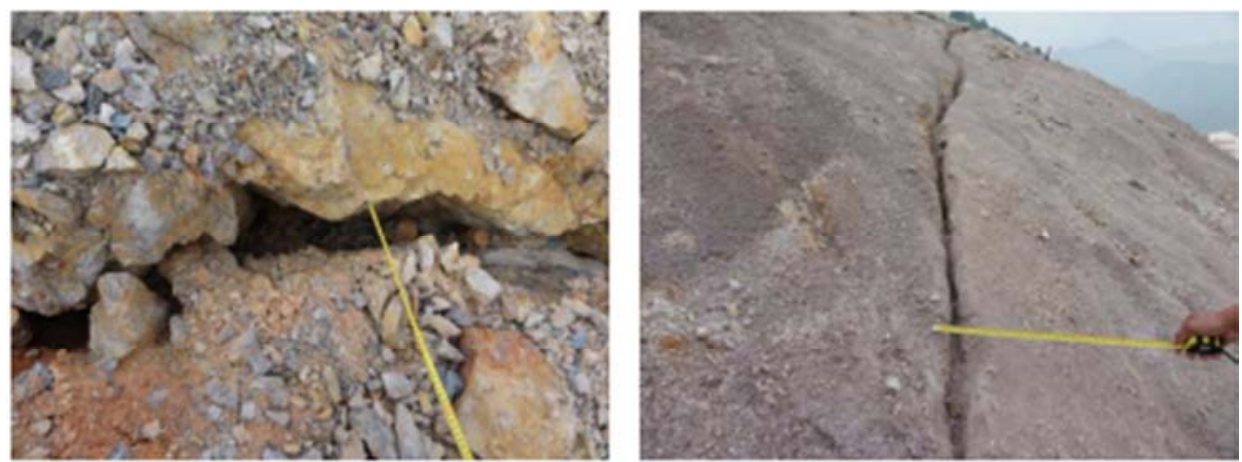

Figure 3. The extensional cracks on trailing edge.

\section{Designs of Research Plans}

\subsection{Design of Experimental Samples}

Firstly, numbering and grouping the undistributed samples in landslide zone by using control variable method. Then dealing with the numbered samples to make sure that there are some differences in moisture contents and dry-wet circulation times between each group in order to make further research 
and analysis in later steps. The allocation of treated sample in each group has been shown on Chart 1

Table 1. The group distributions of treated undisturbed samples.

\begin{tabular}{lll}
\hline $\begin{array}{l}\text { Under different moisture } \\
\text { condition }\end{array}$ & Group number & Moisture contents (\%) \\
\hline \multirow{4}{*}{ Saturated condition } & D-1 & 32.2 \\
& D-2 & \\
Sub-drying condition & E-1 & \\
& E-2 & 24.9 \\
Natural drying condition & F-3 & \\
& F-1 & \\
& F-3 & 9.8 \\
1 time dry-wet circulation & G-1 & \\
& G-3 & 32.2 \\
& H-1 & \\
3 times dry-wet circulation & H-2 & 32.2 \\
& H-3 \\
\hline
\end{tabular}

\subsection{The Plan of X-Ray Diffraction Experiments}

Taking some pulverous undisturbed samples in several groups, by applying Germany Bruker AXS D 8-Focus X-Ray diffraction instruments to have experiments, to identify mineral components of the undisturbed soil. The diffraction instruments could send out characteristic X-Rays through the ray tube to expose samples. According to different kinds of rays that have been recorded on negative plate, the mineral components and their contents of samples could get by comparing with corresponding spectrum. They are mineral components and contents in soil microstructure respectively.

\subsection{The Arrangements of Quadruple Direct Shear Tests}

Direct shear test is a method which is widely used for testing shear strength of soil. It could provide friction angle and cohesion of soil. During the test process, apply electric quadruple direct shear test instruments to test samples under different moisture content conditions, following the group distribution arrangements in Chart 1. The soil samples will be put under different vertical stresses (showed in Chart 2) and put on horizontal shear forces to shear, and get the shear stress at failure. Then the graph of relation (direct stress and shear stress) could be determined. According to Coulomb's criteria, the friction angle and cohesion could also be available.

Due to the fact that the main research purpose is to figure out influences of rainfall for slope stability, it is necessary to have quadruple direct shear tests for undisturbed soil samples under different moisture contents, dry-wet circulation times and dry condition to get their shear strength individually. The specific arrangements of tests are shown below in Chart 2.
Table 2. The arrangements of quadruple direct shear tests.

\begin{tabular}{|c|c|c|c|}
\hline $\begin{array}{l}\text { Under different moisture } \\
\text { condition }\end{array}$ & $\begin{array}{l}\text { Group } \\
\text { number }\end{array}$ & $\begin{array}{l}\text { Moisture } \\
\text { contents (\%) }\end{array}$ & $\begin{array}{l}\text { Vertical } \\
\text { stress (kPa) }\end{array}$ \\
\hline \multirow{3}{*}{ Saturated condition } & D-1 & \multirow{3}{*}{32.2} & 100 \\
\hline & D-2 & & 200 \\
\hline & D-3 & & 300 \\
\hline \multirow{3}{*}{ Sub-drying condition } & E-1 & \multirow{3}{*}{24.9} & 100 \\
\hline & E-2 & & 200 \\
\hline & E-3 & & 300 \\
\hline \multirow{3}{*}{ Natural drying condition } & F-1 & \multirow{3}{*}{9.8} & 100 \\
\hline & $\mathrm{F}-2$ & & 200 \\
\hline & F-3 & & 300 \\
\hline \multirow{3}{*}{1 time dry-wet circulation } & G-1 & \multirow{3}{*}{32.2} & 100 \\
\hline & G-2 & & 200 \\
\hline & G-3 & & 300 \\
\hline \multirow{3}{*}{3 times dry-wet circulation } & $\mathrm{H}-1$ & \multirow{3}{*}{32.2} & 100 \\
\hline & $\mathrm{H}-2$ & & 200 \\
\hline & $\mathrm{H}-3$ & & 300 \\
\hline
\end{tabular}

\subsection{Analysis of Soil Microstructure}

\subsubsection{Instruments and Analysis Methods}

During this scanning test, SU 8010 Field Emission Scanning Electron Microscope of Hitachi was used as instrument. The images which got from scanning were denoised with Image $\mathbf{J}$ software and binarization so that the further specific qualitative and quantitative analysis could be maded. During the process of making samples for scanning tests, samples should be kept dry to make sure the vacuum degrees of vacuum system in scanning instrument. Also, the samples were wrested by hands to broken, wiped off disturbing particles on surface and plated before scanning.

\subsubsection{Analysis of Data}

According to the electron scanning, the images of different magnification times and different viewing points could get. Using the image pre-treated and binaryzation threshold segmentation function of Matlab, the pores and particles in soil samples could be separated from each other. Then applying the bwlabel and regionprops function in Matlab, the microstructural parameters like area, perimeter and roundness of figures could get. The specific process and calculation are showed below:

(1) Area (S) and Perimeters (L)

The images which have been treated by binarization are monochrome images with two gray values (" 0 " and " 1 "). The gray value " 0 " represents pores and grey value " 1 " are for particles. In order to distinguish the unconnected figures to calculate its area and perimeters respectively, figures should be numbered. And the area and perimeter could be calculated by counting pixel contents of the target figures.

(2) Roundness (R)

Roundness (R) is the measure of how closely the shape of particles approach that of a circle, the calculation equation is: 


$$
R=4 \pi S / L^{2}
$$

In above equation, $\mathrm{S}$ means the area, $\mathrm{L}$ represents the perimeters. The larger the value of $\mathrm{R}$ is, the closer the particles are to circle.

\section{Qualitative Analysis of Soil Microstructure}

\subsection{Analysis of Mineral Components in Soil Samples}

The Figure 4 is the typical diffraction patterns of tuff residual soil. According to it, it is apparent that the mainly mineral components of tuff residual soil are quartz, montmorillonite, illite and hematite, and their contents are $65 \%, 15 \%, 12 \%$ and $8 \%$ respectively. The engineering properties of soil, especially its mechanical properties, greatly depend on its material composition and structural characteristics. If there are a great amount of granular minerals in soil, it could increase permeability. The content of montmorillonite is $15 \%$ in tuff residual soil, which means it has a strong water-absorbing quality, it would be soften and expansion under water condition. With the function of water, it will form electric double layer and will increase the thickness of film water, increase the space between particles and weaken the cohesion to result in slipping of particles. So under a plenty rainfall conditions, the soil mass would have some failures due to the weak cohesion and strong slipping ability between soil particles.

\section{3-380-TX3-yogntai}

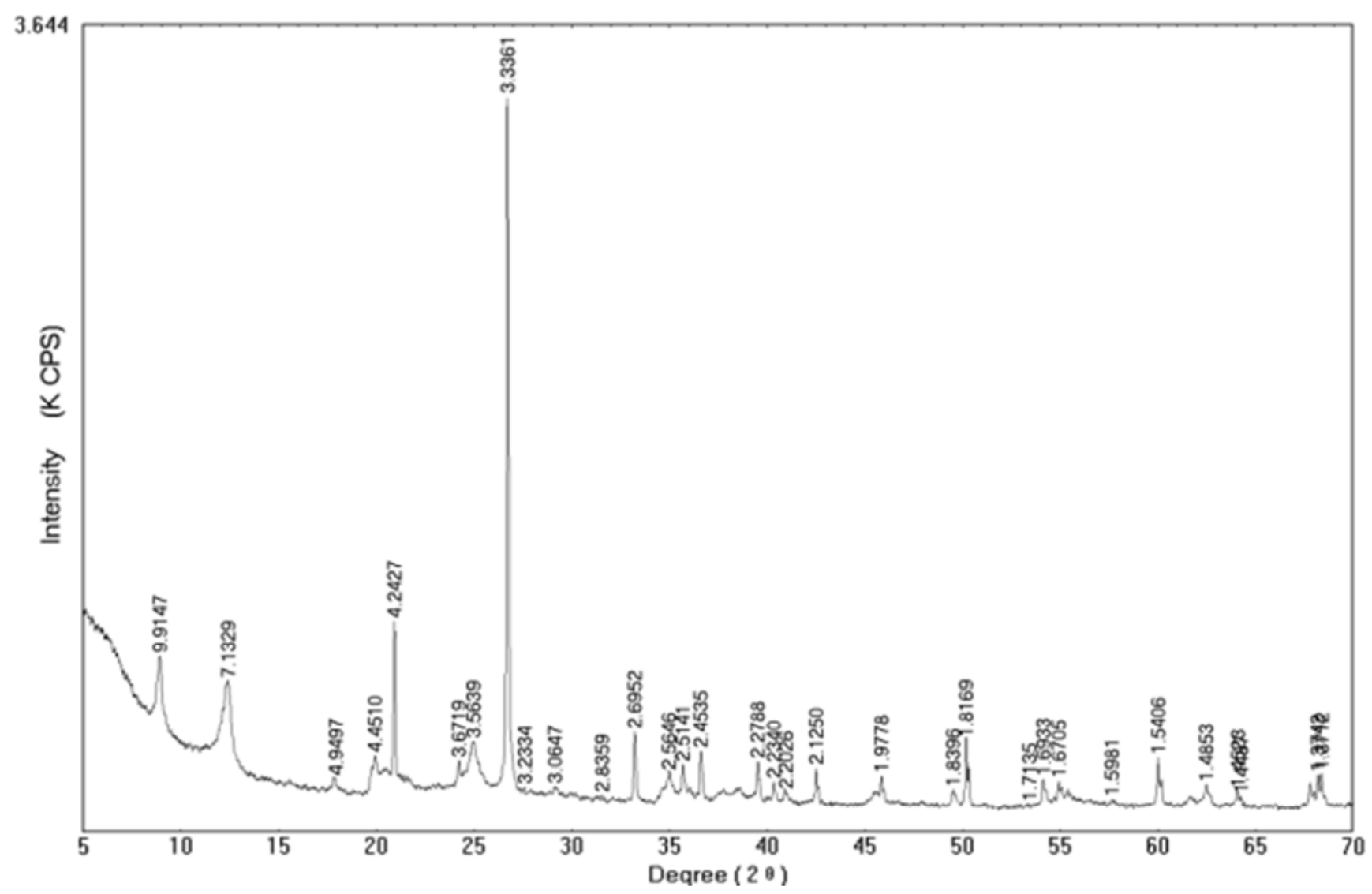

Figure 4. The typical diffraction patterns of tuff residual soil.

\subsection{Qualitative Analysis of Microstructure}

According to the Electron Microscope scanning tests, the microstructure images of soil samples under different conditions have been produced. And the results of surveys and investigations show that the rainfall is the main reason that leads to landslide in this area. The Graph 5 below are the microstructural images of different initial conditions. 


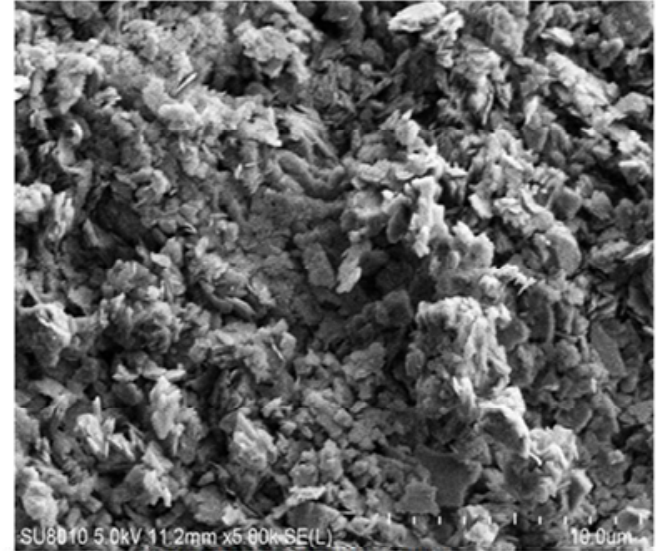

(a) Undisturbed sample

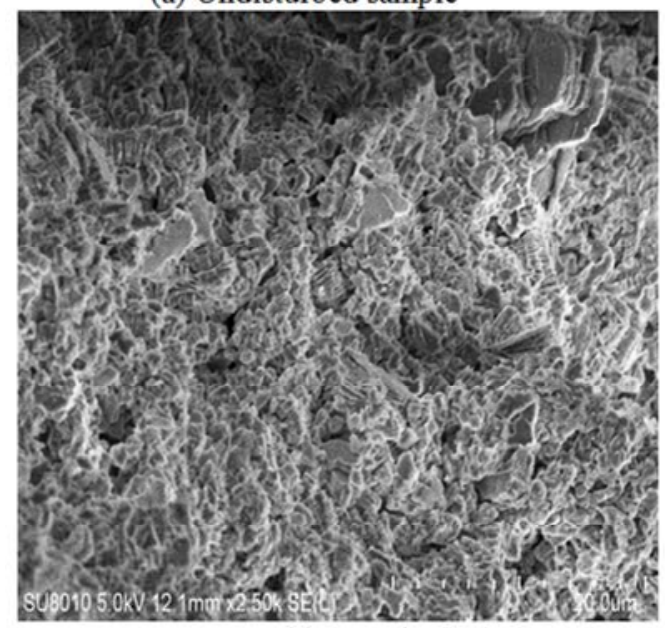

(c) Sample No.G-1

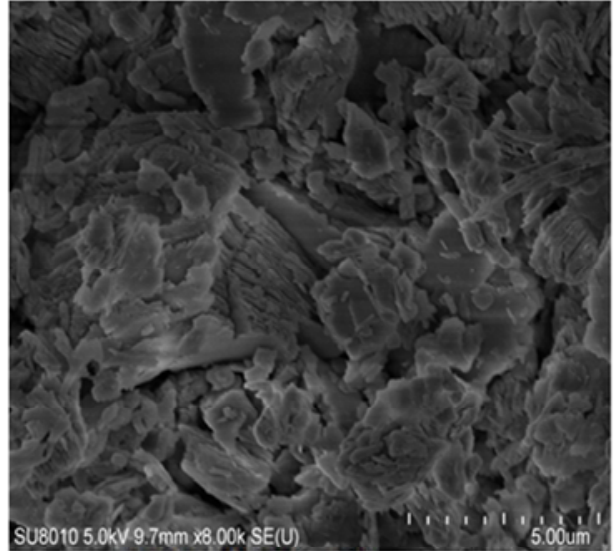

(b) Sample No.D-1

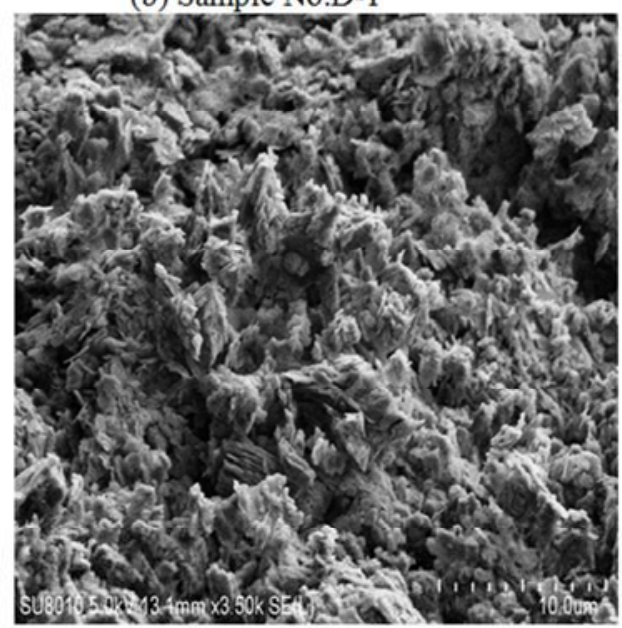

(d) Sample No.H-1

Figure 5. The typical microstructure images of tuff residual soil.

From Figure 5, it is apparent to get the conclusions below:

(1) There are many granular quartz and schistose clay minerals that could be observed in images. Also, some pores between soil particles have been filled with clay minerals. Under long-term leaching and alteration process, the particle arrangements in undisturbed soil samples are much looser. A great amount of small pores could be observed in surface and also big pores are shown occasionally.

(2) In saturated samples and samples with wet-dry circulation, particles tend to be conglobate, with the influence of some stresses. In saturated samples, laminated clay minerals are attached to surfaces of particle or filled in pores. Due to the fact that the particles of tuff residual soil are small, with the influences of capillary forces and suction expansion of clay minerals, pores in saturated sample present to be connected. Under same stress, the more dry-wet circulation time is, the looser particle arrangement of soil is. It could be proved by $\mathrm{H}-1$ sample. In $\mathrm{H}-1$ sample, particles are mainly face-face connected, with apparent directionality and small fractures which exist among particles.

(3) Combining all microstructural images above, its microstructure could be judged as lamination. This structure is often shown on clay minerals of surface-surface or surface-edge connected, with less granular particles inlaying inside. In G-1 sample, particles arrangements are disordered, loose and presented as liminated structure. The connected types are main showed as face-edge, corner-edge which would be disturbed easily as many pores. The reason which lead to this phenomenon is that there are great many of hydrophilic minerals, developing of pores between particles or existing of ferric ions dissolved in water. All of these could accelerate the disintegration of soil mass and cause failures.

\section{Quantitative Analysis of Soil Microstructure}

\subsection{Quantitative Analysis of Microstructure}

By applying the bwlabel and regionprops functions in Matlab, the microstructure parameters (area, perimeter and roundness ect.) of soil samples could get. The specific calculation processes are showed below:

1. Importing pictures which have been de-noised and binarized of each group to Matlab

2 . Couting the numbers of " 0 " in binarized images. The values of matrix could be calculated first, and then minus the total numbers of " 1 " in matrix, the left numbers are for " 0 ".

According to the research and calculation methods above, the parameters of testing samples could get and showed on Chart 3 . 
Table 3. The parameters of soil microstructure porosity.

\begin{tabular}{llllll}
\hline Sample number & Number of pores & Average porosity & Average porosity area & Average perimeter & Roundness \\
\hline D-1 & 2580459 & 52.50 & 90384.56 & 5787.02 & 0.0339 \\
D-2 & 1068255.43 & 44.98 & 204189.86 & 7707.38 & 0.0432 \\
D-3 & 511120.55 & 41.60 & 239479.64 & 12427.82 & 0.0195 \\
E-1 & 540136.67 & 43.96 & 2503.89 & 422.25 & 0.1765 \\
E-2 & 473541.6 & 38.54 & 288689.2 & 16266.71 & 0.0137 \\
E-3 & 510974.33 & 41.58 & 269929.78 & 19251.73 & 0.0092 \\
F-1 & 562145.14 & 45.75 & 179493.42 & 14407.84 & 0.0109 \\
F-2 & 448780.78 & 36.53 & 86569.44 & 4825.99 & 0.0467 \\
F-3 & 478931.5 & 38.98 & 18998.67 & 535.65 & 0.0832 \\
3 times of wet-dry circulation & 578673.56 & 47.09 & 201335.11 & 16641.98 & 0.0091 \\
1 time of wet-dry circulation & 469330.13 & 38.19 & 47516.25 & 2572.10 & 0.0902 \\
Undisturbed soil & 512496.13 & 41.71 & 345544.25 & 20004.83 & 0.0109 \\
\hline
\end{tabular}

\subsection{The Influences of Moisture Contents for Microstructure Characteristics}

Firstly, vertical stress should be controlled to be constant to figure out the influence of moisture contents for soil microstructure. Then, compare the data in groups which owe same vertical stresses but different moisture contents (D-1 E-1 F-1, D-2 E-2 F-2 and D-3 E-3 F-3) and draw the relative analysis curves, showed in Figure 6.
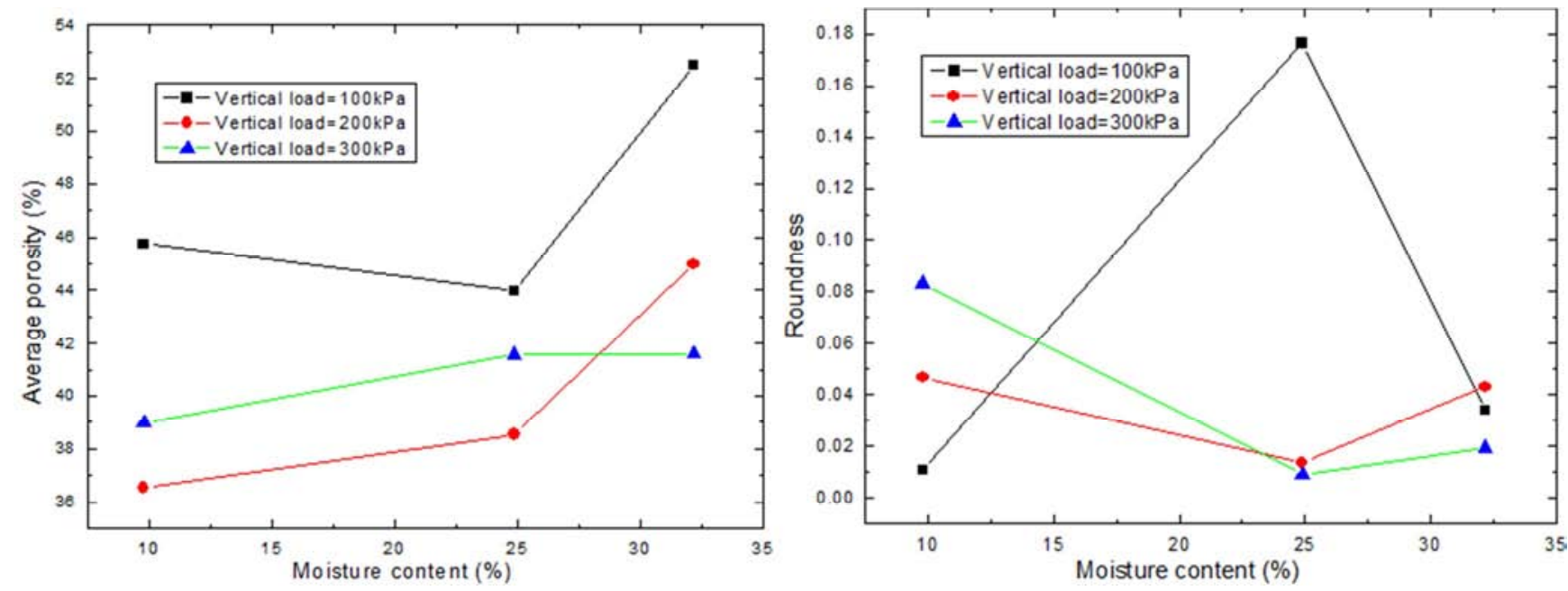

Figure 6. The relation curves of porosity quantitative parameters and moisture contents.

Conclusions made with above graphs:

(1) When vertical stress is constant, comparing with groups of $\mathrm{D}, \mathrm{E}$ and $\mathrm{F}$, it is apparent the changes of soil structure would be greater and stability of soil structure is weaker when moisture content is higher. It is mainly due to the fact that there are some sensitive mineral components in soil, like illite and montmorillonite. The pores have been divided into smaller holes which would increase tortuosity. But filament minerals are easy to be washed away by water and block the pores and pore canal. So the soil microstructures would be broken and changed greatly, so does its strength.

(2) The influence of moisture contents to microstructures of soil also presents as fluctuation status. The reason which causes this phenomenon is quite complex. One the one hand, the dry-wet circulation times may have a great impact on soil microstructure which showed as increasing of porosity contents, worsening of directional alignment. On the other hand, soil sample does not keep constant changing tendency.
From graphs above, when moisture content is about $25.3 \%$, porosity content is in minimum status. Around this point, the directional alignment weakened first and strengthened later and roundness was greatly less influenced with moisture content. In general, when moisture content is $25.3 \%$, the directionality of pores is worse, and with less porosity, higher sliding friction and occlusal friction between particles. So it could prove that the strength of soil is higher when moisture content is $25.3 \%$. It conforms to the result of shear tests.

\subsection{The Influence of Vertical Stress to Microstructure of Soil}

It is the same method like discussed in 5.2. When making research on the relation of microstructure and vertical stress, moisture contents should be kept constant. Compare data in group D-1 D-2 D-3, E-1 E-2 E-3 and F-1 F-2 F-3 and draw the relation curve like below in Figure 7. 


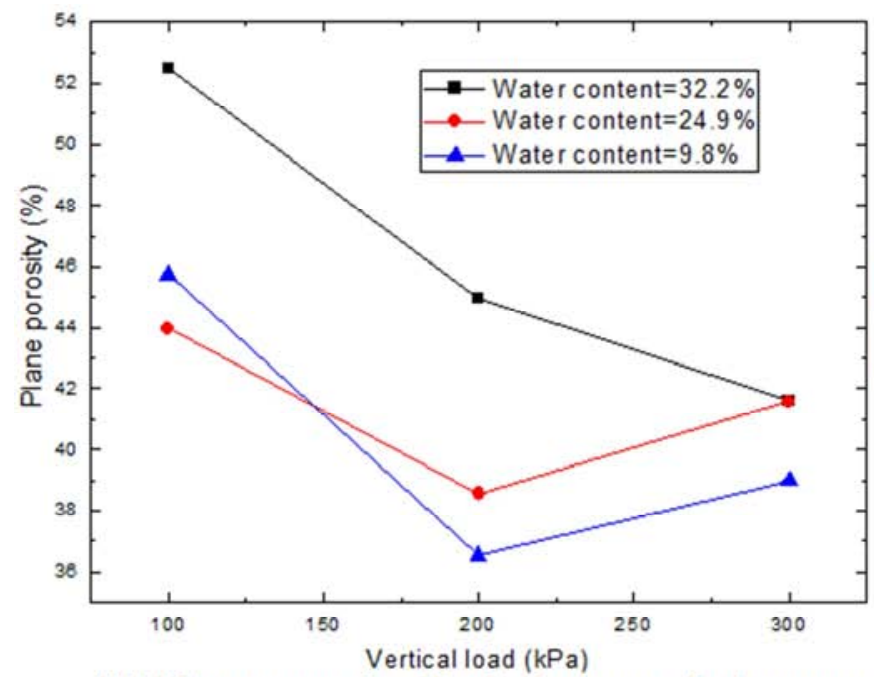

(a) Plane porosity-Vertical stress relation curve

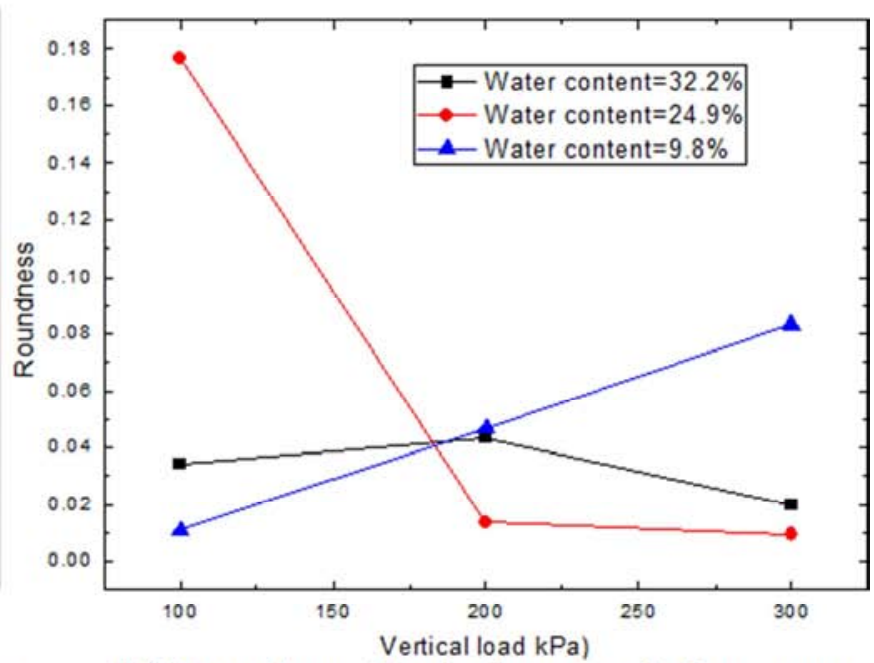

(b) Roundness-Vertical stress relation curve

Figure 7. The relation curves of porosity quantitative parameters and vertical stress.

Concluded from above graphs:

(1) Influences of vertical stress: Comparing the three samples in Group D, when the moisture content keep constant, it is obvious that the quantity of pores increases, the size of pores reduces and the directional alignment of pores is more apparent with increasing of vertical stress. And the structure of soil is changed from honeycomb shape to laminated structure. The porosity also presents tendency of decreasing. When vertical stress reaches $300 \mathrm{kPa}$, soil structure failures and the arrangements of soil particles become disordered. This rule is also showed in samples of Group E and F.

(2) When analyzing the relation of vertical stress and roundness, according to above charts and graphs, it is not hard to find that when the vertical stress is constant, under different moisture content condition, there is no apparent relation of these two factors. But based on the data and relative references,

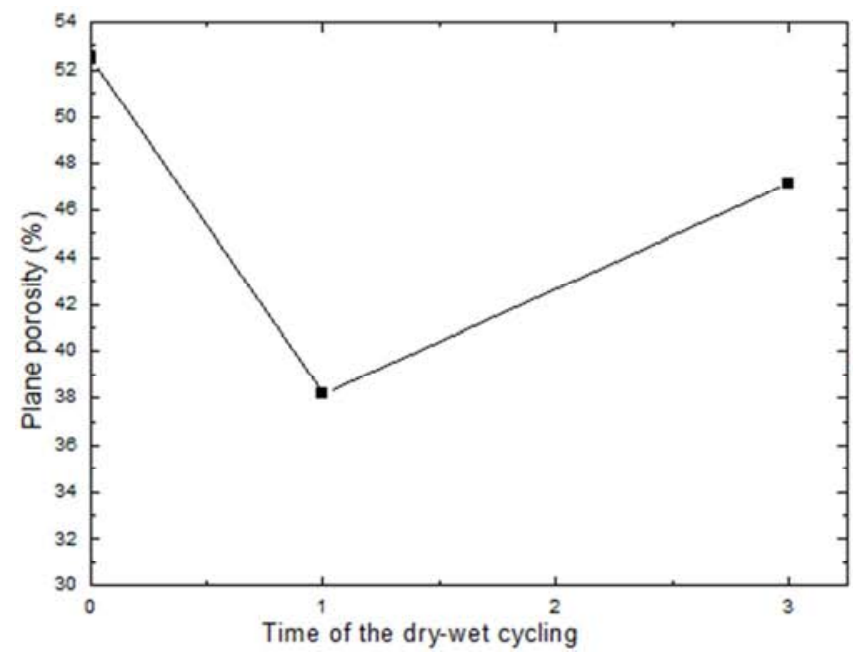

it can be concluded and judged as two guesses below. Guess A: There is no direct relation or no relation of these two factors. They are both independent and have nothing influencing on each other. Guess B: There is some certain relation between these two factors. But their relation is greatly complicated and controlled by many factors. It cannot be get directly from analyzing one influencing factor.

\subsection{The Influence of Wet-Dry Circulation Times to Microstructure of Soil}

When making analysis on relation between soil microstructure and wet-dry circulation times, moisture content is the factor which needs to be kept constant. Compare the data in Group D, G and $\mathrm{H}$ could help to draw the analytical relation curves below, showed in Figure 8.

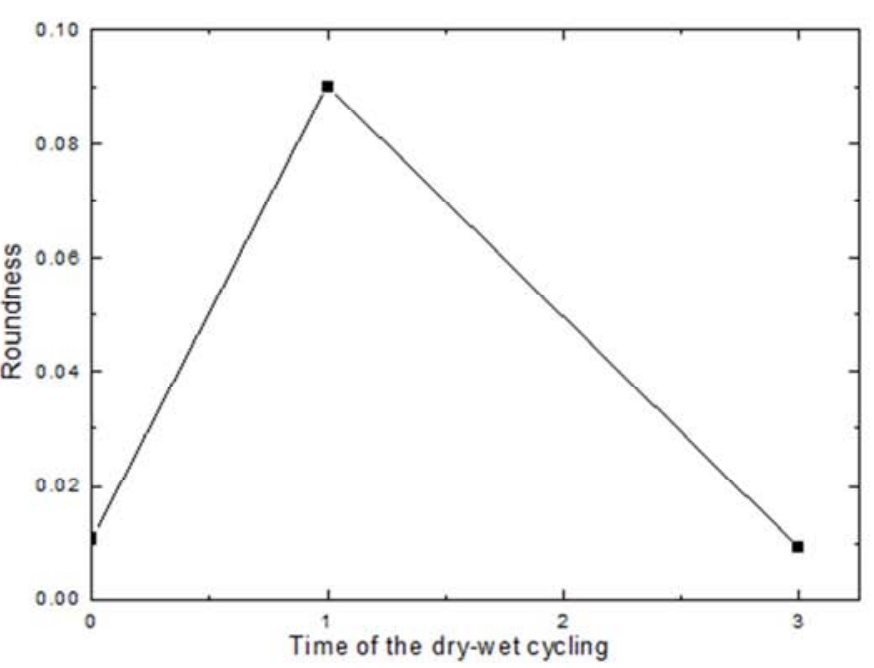

Figure 8. The relation curve of quantitative porosity parameter and dry-wet circulation times.

Conclusion from analysis based on above charts and graphs

(1) The porosity is highest when the sample is under saturated status. After experiencing one time wet-dry circulation, the porosity is changed to the minimum status. After three times circulation, the value of porosity increases a little when comparing with the value in one time circulation. 
So, the conclusion below could get based on analysis and data. The sample in saturated condition owes lower degree of density and high porosity. However, after one time wet-dry circulation time, the sample will be denser which means the porosity would be lower comparing with saturated sample. As for samples experienced several times of wet- dry circulation, its inner microstructure may have been broken and failed greatly which leads to the lower stability performance.

(2) The influence of rainfall (wet) and transpiration (dry) have made soil suffered the influence of dry-wet circulation. After one-time circulation, the changes in soil structure are not apparent which have showed in Group G samples. The changes includes that a little increasing of pores quantity, with relative equilibrium of pore distribution and apparent directional alignment of particles. After three-time circulation, the samples in Group $\mathrm{H}$ owe a higher void ratio, porosity and worse directional alignment or disordering of particles. The platy particles are broken greatly with reducing of particle sizes (changing from 4 5 um to $0.5 \sim 2.5 \mathrm{um}$ ). Soil structure is also changed from laminated structure to flocculated, with a worse structural stability. The microstructure is changed due to the gathering and rearrangement of soil particles. And it would eventually lead to the changing of soil mechanical properties.

\section{The Attenuation Mechanism the Soil Under Rainfall Condition}

\subsection{Analysis on Shear Strength of Soil Samples}

According to the Coulomb's Criterion and some analysis of the data, the shear strength parameters are showed on Chart 4.

Table 4. The parameters of strength and the direct shear test results under different initial conditions.

\begin{tabular}{|c|c|c|c|c|c|c|}
\hline Under different conditions & Group number & $\begin{array}{l}\text { Moisture contents } \\
(\%)\end{array}$ & $\begin{array}{l}\text { Vertical stress } \\
(\mathrm{kPa})\end{array}$ & Shear stress (kPa) & Cohesion $c^{\prime}(\mathbf{k P a})$ & $\begin{array}{l}\text { Friction angle } \\
\varphi^{\prime}\left({ }^{\circ}\right)\end{array}$ \\
\hline \multirow{3}{*}{ Saturated condition } & D-1 & \multirow{3}{*}{32.22} & 100 & 94.89 & \multirow{3}{*}{31.14} & \multirow{3}{*}{$31.52^{\circ}$} \\
\hline & D-2 & & 200 & 158.64 & & \\
\hline & D-3 & & 300 & 221.88 & & \\
\hline \multirow{3}{*}{ Sub-drying condition } & E-1 & \multirow{3}{*}{24.9} & 100 & 116.95 & \multirow{3}{*}{51.71} & \multirow{3}{*}{$33.12^{\circ}$} \\
\hline & E-2 & & 200 & 182.19 & & \\
\hline & E-3 & & 300 & 245.56 & & \\
\hline \multirow{3}{*}{ Natural drying condition } & F-1 & \multirow{3}{*}{9.8} & 100 & 105.25 & \multirow{3}{*}{40.63} & \multirow{3}{*}{$32.87^{\circ}$} \\
\hline & $\mathrm{F}-2$ & & 200 & 169.87 & & \\
\hline & $\mathrm{F}-3$ & & 300 & 234.68 & & \\
\hline \multirow{3}{*}{1 time of wet-dry circulation } & G-1 & \multirow{3}{*}{32.22} & 100 & 90.96 & \multirow{3}{*}{28.67} & \multirow{3}{*}{$31.92^{\circ}$} \\
\hline & G-2 & & 200 & 153.25 & & \\
\hline & G-3 & & 300 & 215.55 & & \\
\hline \multirow{3}{*}{3 times of wet-dry circulation } & $\mathrm{H}-1$ & \multirow{3}{*}{32.22} & 100 & 85.25 & \multirow{3}{*}{24.76} & \multirow{3}{*}{$31.17^{\circ}$} \\
\hline & $\mathrm{H}-2$ & & 200 & 145.74 & & \\
\hline & $\mathrm{H}-3$ & & 300 & 206.23 & & \\
\hline
\end{tabular}

\subsection{The Relationship Between Shear Parameters and Microstructure Parameters}

\subsubsection{The Relationship Between Plane Porosity and Cohesion}

According to comparing the most representative data in Chart 3 and Chart 4, the Figure 9 could get like below:

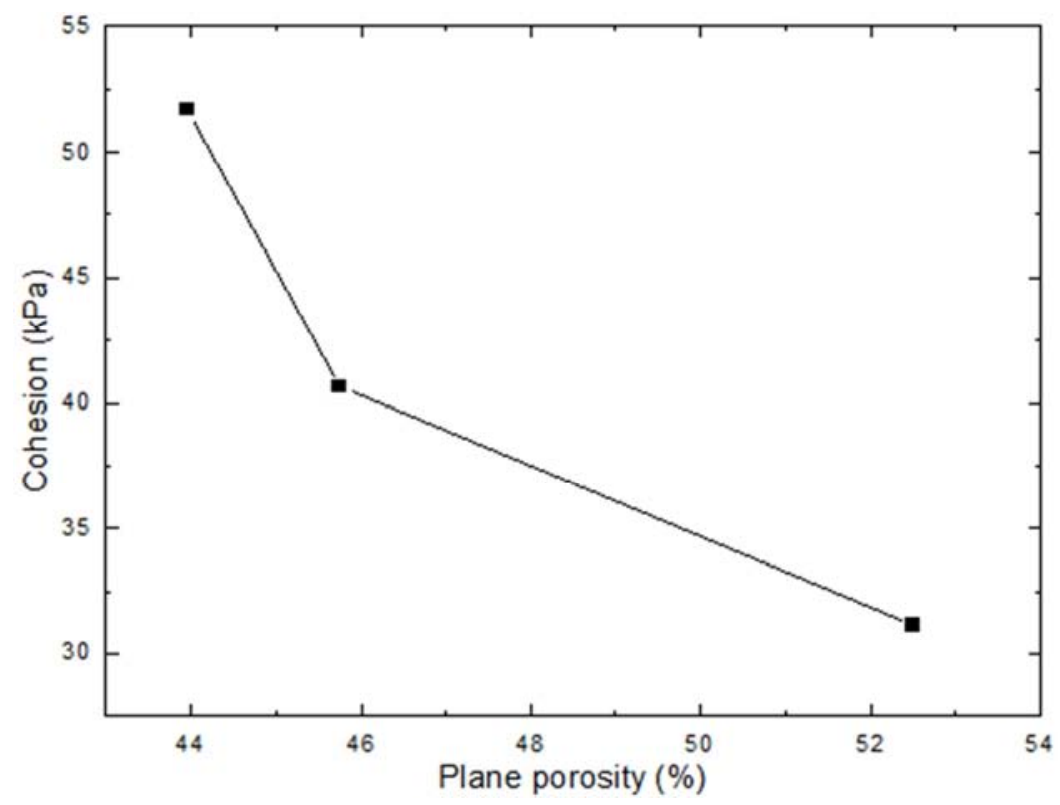

Figure 9. The relationship between plane porosity and cohesion. 
According to above graph, some judgments about the relation of plane porosity and cohesion could be made roughly based on the data. When plane porosity increases, the cohesion of soil samples gradually presents the tendency of decreasing. By making some analysis about the curve, the function about plane porosity (x) and cohesion (y) could be established:

$$
y=-2.53 x+159.67
$$

\subsubsection{The Relationship Between Plane Porosity and Friction Angle}

According to comparing the most representative data in Chart 3 and Chart 4, the Figure 10 could get like below:

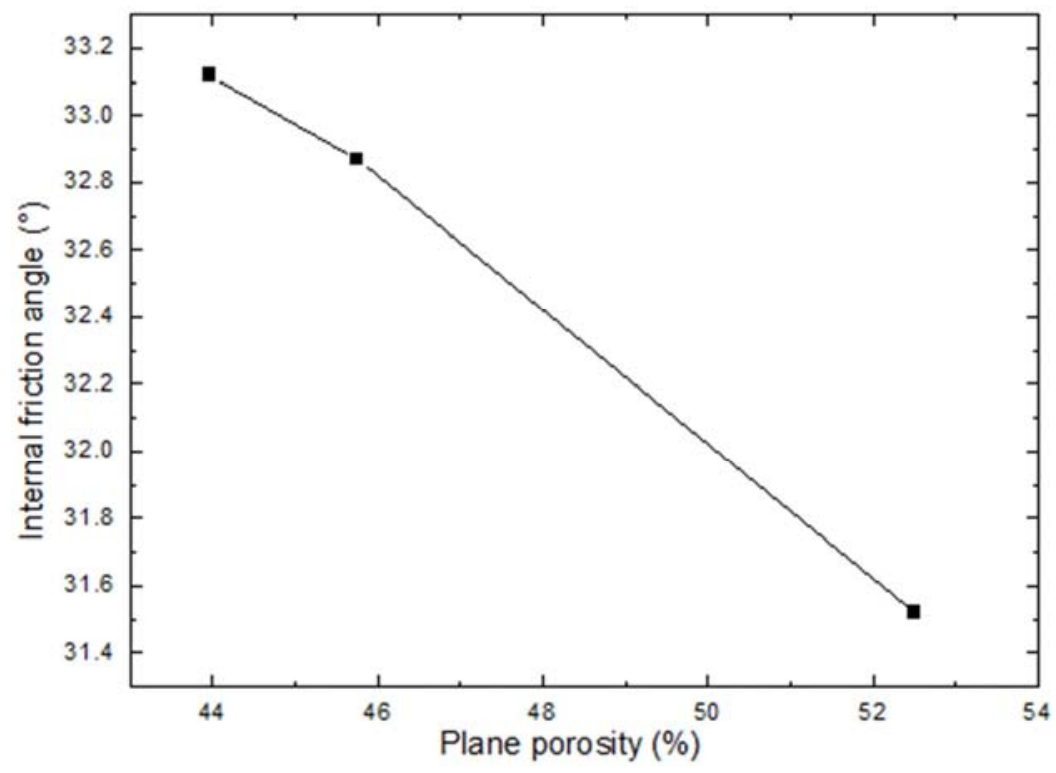

Figure 10. The relationship between plane porosity and friction angle.

According to some analysis based on above graph, it is not hard to find that the relationship of friction angle and plane porosity is linear generally. When plane porosity increases, the friction angle gradually reduces. And the function of plane porosity $(\mathrm{x})$ and friction angle (y) could also be established based on the data on graph 10 :

$$
\mathrm{y}=-0.19 \mathrm{x}+41.61
$$

\subsubsection{The Relationship Between Roundness and Friction Angle}

According to comparing the most representative data in Chart 3 and Chart 4, the Figure 11 could get like below:

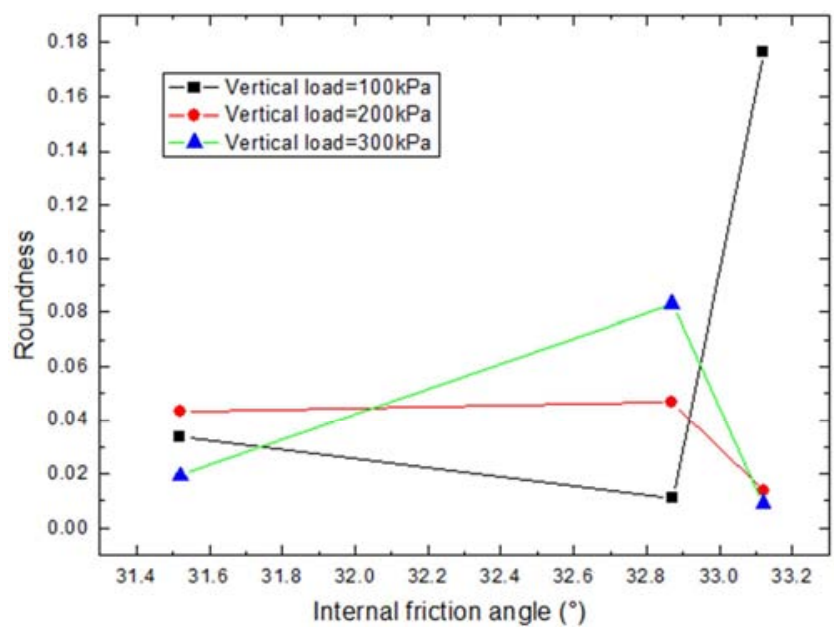

Figure 11. The relationship between roundness and friction angle.
According to the analysis based on graph 11, there is no apparent tendency relationship between roundness and friction angle. More significantly, when soil sample is under $100 \mathrm{kPa}, 200 \mathrm{kPa}$ and $300 \mathrm{kPa}$ of vertical load, the relationships are completely different for these 3 groups. So, it is impossible to figure out a clear relationship of these two variates. But when the friction angle is about $32.7^{\circ}$, the tendency of three lines all changed apparently. So the value of $32.7^{\circ}$ is possible to be a critical state of this soil samples.

\subsubsection{The Relationship Between Roundness and Cohesion}

According to comparing the most representative data in Chart 3 and Chart 4, the Figure 12 could get like below:

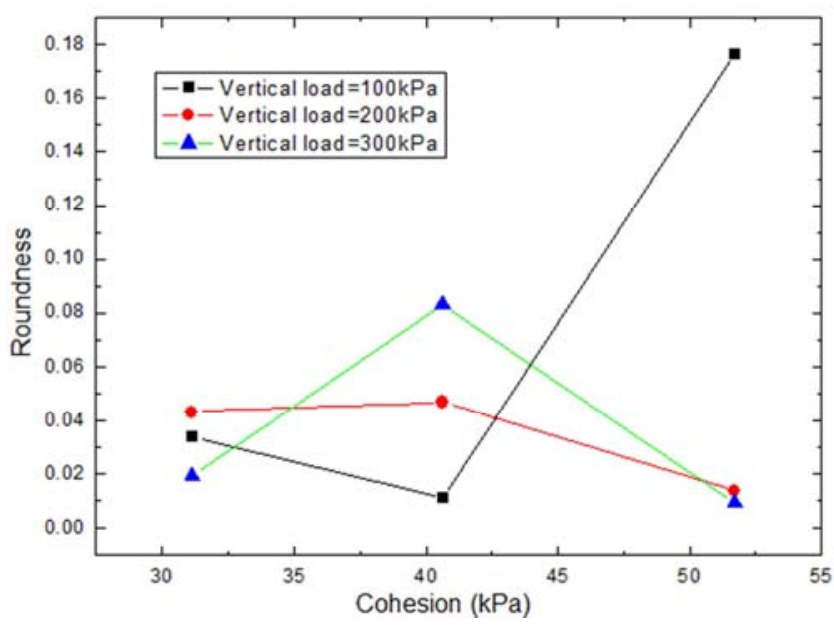

Figure 12. The relationship between roundness and cohesion. 
From analysis based on Graph 12, it could be concluded that the relation between roundness and cohesion is not clear. When vertical stress is $100 \mathrm{kPa}$, roundness reduces with increasing of cohesion values. When cohesion is above $41 \mathrm{kPa}$, roundness starts to increase greatly with increasing of cohesion. But when vertical stress is $200 \mathrm{kPa}$ and $300 \mathrm{kPa}$, roundness increases when cohesion increases in early stage. After cohesion reaches $41 \mathrm{kPa}$, roundness start to decrease with rising of cohesion. So it is not possible to describe their relation clearly from this graph only. But it is significant and apparent that the relation tendency of cohesion and roundness is different under different vertical stress. And it also could be judged that when cohesion is about $41 \mathrm{kPa}$, the tendency of their relation may be changed completely.

\subsection{The Attenuation Mechanism the Soil Under Rainfall Condition}

According to above analysis, due to the fact that there are feldspar, pyroxene and hornblende as mineral component which would form a great amount of clay minerals in residual slopes which formed by weathering of igneous rocks, this kind slope would easily have some failures which caused by pores increasing, mineral microstructure broken and shear strength parameters lowering under rainfall.

\section{Conclusions}

This test by analyzing the microstructures of soil treated with different moisture contents including relevant parameters such as average porosity, average pore area and perimeter, quantity of pores and roundness has analyzed the influence of moisture content and times of dry-wet circulation on the microstructure of soil. The qualitative analysis may reveal that a more intuitive structural differences contrast impression can be concluded by using the electron microscope scanning photos of the soil microstructure and internal mineral composition of the differences in a detailed comparison. At the same time, by the qualitative analysis and calculation of each important parameters, comprehensive understanding and analysis of relevant data can be used to obtain how the external effects influence through the internal structure of the soil and its relevant parameters, which ultimately lead to a qualitative change from quantitative change. Through the analysis of experimental phenomenon and summary of related data, the decay mechanism of the unsaturated residual soil under the interaction of soil and water, especially the reason for intensity attenuation analysis on microstructure has the following analysis results.

(1) As for soil-like slope, the interaction between soil and water affects the physical and chemical environment with which the soil microstructure such as the size and distribution of the holes also change. The change of soil holes is one of the internal factors of soil deformation and the main factor that determine the physical and mechanical properties of soil. The characteristics of soil deformation and strength are affected by the soil microstructure changes in different extent so the environment of soil particles has a certain influence on their stability.

(2) The X-diffraction test has showed that the main mineral composition of tuff residual soil is montmorillonite and illite. Their structure is loose and the porosity is large, which is a honeycomb structure. The soil has the characteristics of high sensitivity, low strength, high compressibility, and disintegrated by absorbing water which is the main source of engineering geology influence and provides a material basis for rainfall-induced landslides. To conclude, the mineral composition of the soil is an important factor in structural stability.

(3) FESEM shows that the microstructures of tuff soils are composed of aggregates of columnar and massive pieces of grain and collection of flaky minerals most of which are covered by single grains (quartz particles) with higher contents and in grains of clay minerals in edge-face or faceface contacted.

(4) Under the same water content, with the increase of vertical load, the flat porosity and the average pore area decrease and the sample particles are more compact whose orientation is more obvious. The roundness of the pores increases, and the damage of the soil structure is more serious. Therefore, under the same water content conditions, the greater the vertical load the soil is, the more serious damage to the soil structure it will bring.

(5) Under the condition of water content ratio changes and dry-wet circles, through a wet - drying process, the change of sample soil structure status is not obvious, and there is a small increase in intergranular pores, and the grain orientation is obvious. After three wet and dry cycles, the porosity of the sample particles increased greatly, the grain orientation will be deteriorated, the arrangement will be disordered, the flaky particles will be crushed and the particle size will become smaller, and the soil has been transformed from laminar structure to flocculent structure. Therefore, it can also be concluded that the number of different wet-dry circulation time has a great effect on the same soil stability c especially in microstructure.

\section{References}

[1] Shiyi Yang. The research of landslide prediction and landslide classification system [D]. Wuhan: Wuhan university of science and technology. 2010.

[2] Huang Runqiu. The greatest landslide research and their occurrence mechanism since $20^{\text {th }}$ century $[\mathrm{J}]$. Chinese journal of rock mechanics and engineering, 2007, 26 (3): 433-454.

[3] Ma Deyi. Analysis of a double-layer heterogeneous loess landslide occurrence mechanism and its controlling measures [D]. Xi'an: Xi' an University of Technology. 2014.

[4] Shao Lianfen, Peng Zuwu, Wang Shuonan, ect. A classification of the launching mode in Luanchuan landslide under storm [J]. Journal of Mountain Science. 2013. 31 (3): 334-341.

[5] Cruden DM, Varnes DJ. Landslide types and processes. Landslides, investigation and mitigation. 1996. 
[6] Hoek E, Bray J W. Rock Slope Engineering. 1981.

[7] Zhou Xin. The research of high-speed remote landslide air cushion effect caused by earthquake [D]. Shanghai: Shanghai Jiaotong Univeristy. 2010.

[8] Erismann, TH, Abele, G. Dynamics of rockslides and rockfalls. 2001.

[9] Xin Aiguo, Gao Guangyun, Chen Longzhu. The research of hydrokinetics mechanism in high-speed landslide [J]. Chinese journal of rock mechanics and engineering. 2004. 23 (4): 607-613.

[10] He Xuwen. Analysis of rock slope stability based on discrete unit method [D]. Xiangtan: Xiangtan University. 2010.

[11] Xu Jiancong, Shang Yuequan. The mechanism of disintegration and deformation of debris landslide under rainfall condition [J]. Rock and Soil Mechanics. 2008. 29 (1): 106-112.

[12] $\mathrm{Xu}$ Jiancong. The stability and failure mechanism of deformation and disintegration of debris soil landslide [D]. Hangzhou: Zhejiang University. 2005.

[13] Cheng Qiangong, Hu Houtian, Peng Jianbing. The mechanism of lateral locking plane rotary landslide dynamic [J]. Chinese journal of rock mechanics and engineering. 2000. 19 (5): 634-639.

[14] Cheng Qiangong. High-speed rock landslide dynamics [D]. Chengdu: Southwest Jiaotong University. 1999.

[15] Liang Xiaoyong, Xue Xiaohui, Wang Humei, Creep characteristics of rock time hardening damage [J]. Journal of Liaoning Technical University (Natural Science), 2013. 32 (4): 509-512.
[16] Shi Beixiao. Specific analysis of rock slope in landslide zone with shear tests [D]. Xi'an: Xi'an University of Technology. 2009.

[17] $\mathrm{Wu}$ Yixiang. Qualitative analysis on engineering clayey soil microstructure $[\mathrm{J}]$. The Journal of Chinese Academy of geological sciences.1991.23 (2): 143-151.

[18] Shi Bin, Li Lin, The qualitative research of clayey soil in SEM images [J]. Science in China: A Edition.1995. 25 (6): 666-672.

[19] Xiao Shufang, Aquino K. The structure and strength changing features of mudding catation [M]. Changchun: Jilin Science and technology publishing house, 1991.

[20] Xie, Heping. The application of fractal geometry in soil and rock mechanics [J]. Rock and Soil Mechanics, 1992, 14 (1): 14-24.

[21] Hu Ruilin. The quanlitative model of clayey soil microstructure and its engineering geological features [M], Beijing: Geological Publishing House, 1995.

[22] Wang Qing, Wang Jianping. The fractal geometry research of soil pores [J], Chinese Journal of Geotechnical engineering, 2000, 22 (4): 496-498.

[23] Wang Baojun, Wang Jianping, Liu Zhibin, ect. The fractal research of soil microstructure based on GIS [J], Chinese Journal of Geotechnical engineering, 2004, 26 (2): 244-247.

[24] Shi Bin, Li Li, Jiang Hongtao ect. The application of DIPIX Image Processing System in soil microstructure qualitative research [J]. The journal of Nanjing University. 1996. 32 (2): 275-280.

[25] Qiu Guorong. The mechanism of microstructure controlling in loess subsidence deformation [D]. Lanzhou: Chinese seismological bureau, Lan zhou research institution. 2010. 